\title{
Estudio cualitativo de las funciones adultas. Instrumento de indagación
}

\author{
Qualitative study of adult functions. Instrument of inquiry
}

\author{
Florencia Machini, Patricia Arias \\ machini.florencia@gmail.com, ariaspatricia60@gmail.com \\ Universidad Nacional de la Patagonia Austral \\ Av. Piloto "Lero" Rivera- Río Gallegos - Santa Cruz - Argentina
}

Recibido: 18/05/2021. Aceptado: 15/12/2021

\begin{abstract}
RESUMEN
El proyecto de investigación denominado "Uso y validación clínica de un instrumento de indagación para niños en el campo psicológico y psicopedagógico" (PI 29/A394), busca ampliar el instrumento de indagación para niños creado en el proyecto de investigación "La incidencia de modelos enseñantes en niños que aprenden. Diseño de un instrumento para su análisis" para verificar si las propiedades encontradas en las representaciones de los niños sobre los modelos adultos se conservan en el uso clínico individual.

El estudio se centra en las historias individuales de los sujetos profundizando el conocimiento sobre las posiciones subjetivas de enseñantes padres acerca de la función adulta e identificando en los datos provenientes de la información empírica la convergencia de sentidos de nuevas técnicas de indagación complementarias del instrumento ya diseñado y validado en la investigación que antecede.
\end{abstract}

Palabras clave: Representaciones; posiciones subjetivas; función adulta; técnicas de indagación.

\begin{abstract}
The research project titled "Use and clinical validation of an inquiry instrument for children in the psychological and psychopedagogical field" (PI 29/A394) seeks to expand the inquiry instrument for children created in the research project "The incidence of teaching models in children who learn. Design of an instrument for its analysis" to verify whether the properties found in children's representations of adult models are preserved in individual clinical use.

The study focuses on the individual stories of the subjects, deepening the knowledge about the subjective positions of teaching parents about the adult function and identifying in the data from the empirical information the convergence of senses of new investigation techniques complementary to the instrument already designed and validated in the previous research.
\end{abstract}

Keywords: Representations; subjective positions; adult function; inquiry techniques.

\section{INTRODUCCIÓN}

En el presente informe se exponen las líneas teóricas y metodológicas del PI 29/A394 el cual se inscribe como desarrollo del grupo consolidado Interdisciplina y Aprendizaje, generando conocimiento científico en el campo disciplinar de la Psicopedagogía; así mismo aporta 
saberes a la educación y la psicología, recibiendo también conceptualizaciones de dichas disciplinas.

El recorte de objeto se centra en el estudio cualitativo de las funciones adultas, a fin de profundizar el conocimiento sobre la posición subjetiva enseñante de dichas funciones, estudiando las representaciones de los adultos sobre las funciones educativas y de crianza. Una de las estrategias metodológicas para tal fin, es el desarrollo y aplicación de encuestas a figuras adultas con enfoque e interpretación cualitativa. Además, y tomando en cuenta el contexto impuesto por la pandemia, se implementó una técnica innovadora para comprender el impacto socio-subjetivo de las medidas provenientes del ASPO en niños y niñas.

\section{Marco histórico}

Como fue mencionado con anterioridad, el grupo consolidado "Interdisciplina y Aprendizaje", perteneciente al Instituto Educación y Ciudadanía procura abordajes interdisciplinarios de los objetos de investigación. Busca la problematización del fenómeno del aprendizaje, su situación vincular, los actores intervinientes, las condiciones en las que tiene lugar y las múltiples influencias recíprocas.

Este proyecto posee como antecedentes:

Durante el 2012 al $2014^{1}$ se desarrolló una investigación que se vincula con el estudio de la relación entre las configuraciones familiares y las modalidades de aprendizaje escolar de los hijos en un contexto barrial vulnerable. En el mismo se pudo comprender los desencuentros entre los adultos enseñantes padres y maestros; las representaciones recíprocas mostraron distancias de estas figuras centrales en el desarrollo de los niños. Por ello se consideró fundamental profundizar cómo esto repercute en la internalización de los modelos.

Continuando con esta línea, del 2015 al $2017^{2}$ se indagó sobre la incidencia de los modelos enseñantes en niños que aprenden, diseñándose un instrumento para su análisis el cual se aplicó a una muestra de niños entre los 6 a 10 años. El mismo consiste en 10 láminas en blanco y negro agrupadas en series, donde se observan escenas vinculares entre adultos y niños. En la consigna se le solicita al niño una descripción libre de la imagen, iniciando a partir de ella un diálogo clínico con la intención de profundizar las significaciones establecidas. Una de las conclusiones de ese período, refiere a la caída de la autoridad adulta y la simetrización de vínculos adultos-niños; ello denota la preocupación sobre la incidencia que esos fenómenos tienen en los niños y niñas en desarrollo, especialmente en su subjetivación. Luego la construcción del instrumento requirió un proceso de validación, a través del estudio de casos y otras técnicas complementarias.

En el periodo del 2018 al $2020^{3}$ como se menciona con anterioridad, buscará ampliar el

\footnotetext{
${ }^{1}$ PI. 29/A283-1. "La relación entre las configuraciones familiares y las modalidades de aprendizaje escolar de los hijos, en un contexto barrial vulnerable" (2012 -2014). Director: Arias Patricia; Codirector: Bedacarratx Valeria. Integrantes: Mansilla Silvia; Britos Adriana; Castillo Claudia; Pizzio Ángela; García Silveria; Carbone Pilar; Navarro Silvana.

${ }^{2}$ PI.29/A345. "La incidencia de modelos enseñantes en niños que aprenden. Diseño de un instrumento para su análisis" (2015-2017). Director: Arias Patricia. Integrantes: Carbone Pilar; Castillo Claudia; García Silveria; Mansilla Silvia; Navarro Silvia; Stettler Loreli (Investigadores); Ballesteros Juliana; Honcharuk Yohana; Portas Stefel Flavia (Alumnas).

${ }^{3}$ PI.29/A394-1. "El uso y validación de un instrumento de indagación para niños en el campo psicológico y psicopedagógico" (2018-2020). Director: Arias Patricia. Integrantes: Mansilla Silvia, Castillo Claudia, Carbone Pilar, Rossi Verónica (Investigadores), Honcharuk Yohana (Alumna).
} 
instrumento de indagación ya diseñado y validado, para verificar si las propiedades presentes en las representaciones sobre los modelos adultos se conservan en su uso individual, profundizando el conocimiento sobre las posiciones subjetivas de enseñantes padres y maestros acerca de la función adulta.

\section{Marco conceptual}

Es posible visualizar que el vínculo niño-adulto y su construcción está atravesado por el contexto de inmediatez, liquidez e incertezas. Es importante mencionar que en la presencia del otro se puede ir construyendo saber que proviene de aquel que se ubica subjetivamente como enseñante, y debe ocupar un lugar de sostén y seguridad. La representación internalizada de la autoridad conferida por un niño, es una posición interna que se origina en las figuras parentales y luego en las figuras docentes en la socialización secundaria, quienes también son los encargados de la transmisión de saber. Cuando los adultos son ubicados subjetivamente por los niños en la autoridad podrán situarse en situación de aprendizaje y estar dispuestos a atravesar ese proceso acompañados, sostenidos y enmarcados en un adecuado nivel de certezas y dudas.

Los padres son los que erotizan, prohíben, se constituyen en primeros objetos de amor y odio, son modelos de identificación, portadores de normas y valores, transmisores de cultura (Janín, 2012).

Asociado a esto, merece la pena subrayar cómo la enseñanza es un proceso que se realiza por la interacción de quien enseña, aprende, el objeto de conocimiento y el contexto en el que se produce. No hay que olvidar que se considera como enseñantes a los padres, la familia, docentes, medios de comunicación e incluso a las nuevas tecnologías.

A quien enseña le corresponde pensarse como enseñante y confiar en sus habilidades y capacidades para hacerlo, como también, tener expectativas en quien aprende, su deseo y el placer de enseñar y aprender en un vínculo intersubjetivo. Por tanto, se debe abrir un espacio de subjetividad para el aprendiente, favoreciendo su autonomía y diferenciación. Como lo hace notar Fernández (2002) quien enseña se ofrece como un modelo identificatorio, no para ser imitado, sino para tomar del otro aquello que le permita diferenciarse. Es decir, los primeros enseñantes serán "modelos", adultos significativos para que se de la producción y el despliegue de la subjetividad del niño.

\section{Marco teórico}

Para ahondar en la perspectiva de la comprensión y desarrollar un análisis sólido es necesaria una estructura metodológica científica pertinente.

Conviene especificar que las personas no responden sólo a estímulos, sino que los significados influyen en sus acciones. Estos significados son productos sociales, como también, productos de un proceso de interpretación. Es decir, se tendrá en cuenta que una persona aprende de y con los demás la forma de ver el mundo, y que supone de un proceso continuo de interpretaciones y definiciones.

El marco metodológico de la investigación es cualitativo. Se apoya en la idea de la unidad de la realidad y la fidelidad a la perspectiva de los actores involucrados. Así pues, describe o explica un proceso, la comprensión del tema, los análisis donde se advierta la interacción de los actores, la construcción de significados y el contexto en que actúan.

Entonces, el interés por la indagación de la internalización de los modelos enseñantes por parte de los niños aprendientes y la mutua incidencia en ese vínculo requiere este tipo de abordaje. De esta manera, se tendrá en cuenta a los sujetos, la estructura simbólica y social que los sostiene, las particularidades de su vínculo, sus prácticas y discursos. 
Además, es necesario destacar que se tomaron aportes del método clínico, proveniente de la perspectiva psicoanalítica y psicogenética, permitiendo acceder a las organizaciones psicológicas, cognitivas y psíquicas. Es posible observar que en la investigación que antecede, el instrumento que consta de 10 láminas en blanco y negro con escenas de situaciones vinculares es administrado en una entrevista individual a niños, junto con una libre descripción de cada imagen por medio del diálogo clínico para profundizar las significaciones y proyecciones atribuidas, las posiciones subjetivas de los personajes de la escena y las características del contexto. Es preciso tener presente la importancia de la proyección en esta instancia, ya que la misma surgirá a partir de las imágenes que presentan estímulos poco estructurados refiriendo a situaciones de aprendizaje significadas por el niño en relación a los adultos enseñantes. Irá acompañado de consignas con las cuales confrontar al niño a sus respuestas controlando la consistencia de su pensamiento.

Destacando este aspecto, las técnicas proyectivas son consideradas "instrumentos especialmente sensibles para revelar aspectos inconscientes de la conducta, ya que, permiten provocar una amplia variedad de respuestas subjetivas, son altamente multidimensionales y evocan [respuestas y] datos del sujeto de gran riqueza" (Lindzey, p. 72 1961, citado por Jiménez Cortés 2007).

Continuando con esta línea de pensamiento y teniendo en cuenta la perspectiva clínica se desarrolló un protocolo para indagar acerca de cómo los niños/as estaban atravesando la cuarentena (ASPO y DISPO), a partir del diálogo clínico y el acompañamiento del dibujo.

Hammer (2008) explica que el hombre históricamente utilizó dibujos para registrar sentimientos y acciones, y que el individuo comienza a emplear la comunicación gráfica de manera temprana. Los dibujos proyectivos como así también los sueños expresan conflictos inconscientes por medio del lenguaje simbólico. Además, Delval (1996) citado por Faas (2018) puede ayudar a complementar esta idea, dado que menciona que el dibujo es el medio en el que se relaciona el mundo interno y externo, en donde se muestran los estados de ánimo, sentimientos, ideas, carencias, fortalezas, creatividad, nivel de desarrollo y percepción entre otros aspectos psicoafectivos.

Los dibujos son altamente proyectivos, a partir de estos es posible observar aspectos de la dinámica de la personalidad y la manera en la que estos niños/as atravesaron la cuarentena. Además, el enfoque cualitativo permitió seguir profundizando en relación a la investigación que antecede, diseñando una encuesta de enfoque cualitativo, con preguntas abiertas que permitieran observar la diversidad de respuestas en relación a los tópicos que se plantearon, explicando aquello que piensan.

\section{RESULTADOS ANÁLISIS Y DISCUSIÓN}

\section{Materiales y métodos}

En cuanto al instrumento de indagación creado en el PI-29/A345 como se ha mencionado con anterioridad, se destaca como núcleo problemático el campo del aprendizaje, y la forma en la que los niños internalizan los modelos enseñantes problematizando la incidencia actual de los mismos en su posición subjetiva. En el mismo se reflexionó sobre el lugar del adulto frente a la escolaridad de sus hijos y la puesta en escena de las funciones de sostén y límites. Es decir, ese instrumento proyectivo permitía comprender las internalizaciones sobre los modelos adultos, indagando las relaciones vinculares, contextualizadas en el ámbito familiar y educativo.

El diseño de las láminas buscó representar las situaciones/escenas ya mencionadas y para esto se organizó en tres series: 
Serie A: La posición subjetiva del adulto como enseñante.

Serie B: La posición subjetiva del niño como aprendiente.

Serie C: Adulto y niños en contexto.

De esta forma se haría un análisis sobre el sostén emocional, el riesgo físico, la puesta de límites, autoridad y adjudicación de roles, propiciación del autocuidado, internalización de los modelos, vinculación entre niño-adulto y pares, evaluar el contexto bajo la influencia de la tecnología y la inmediatez, y específicamente la influencia de dichas variables en el aprendizaje.

Con la intención de ampliar la información empírica, se construyeron tópicos a partir de los ejes sobresalientes de los relatos de los niños en el marco de las entrevistas de administración del instrumento:

Tópico 1: Concepciones sobre la infancia. Se recaba información sobre las ideas previas en cuanto a la niñez, las percepciones sobre ésta última en la actualidad, las necesidades de los niños, permanencias y cambios. Se indagará sobre la niñez de los entrevistados y se buscarán recuerdos de sus enseñantes/adultos significativos.

Tópico 2: Creencias sobre lo que significa la función materna/paterna. Se obtendrá información sobre las concepciones de maternidad y paternidad, la construcción de sus funciones como adultos. Aspectos positivos y dificultades de esa función. Modos de resultados de las dificultades.

Tópico 3: Percepciones sobre el mundo actual y su incidencia en la crianza de los hijos. Se hará énfasis en cómo perciben la incidencia del mundo actual en la función adulta, procurando descripciones espontáneas sobre los rasgos de la época y sus apreciaciones positivas y negativas en cuanto a esta.

Tópico 4: Expectativas sobre el desarrollo de sus hijos. Se busca averiguar qué se espera de los hijos, y sobre lo que los adultos creen que tienen para ofrecerles. Intenta hacer visible las demandas hacia los hijos, satisfacciones y frustraciones, perspectivas de futuro y posibles proyecciones en ellas.

Tópico 5: Modalidades de enseñanza. Historia vital. Se procura obtener información sobre la posición subjetiva del adulto en aprendizajes del desarrollo evolutivo, profundizando en las escenas paradigmáticas del mismo: lenguaje, marcha, control de esfínteres, ingreso al nivel inicial y escuela primaria. Se buscan datos sobre la posición del adulto frente a conflictos o dificultades del niño en los vínculos con pares o con otros adultos.

Con el objetivo de dar continuidad a la validación del instrumento, se creó una encuesta con enfoque cualitativo destinada a madres/padres de hijos entre 4 a 10 años, la cual fue online y daba la posibilidad de poder expresar con libertad qué piensan. La misma tuvo en cuenta los tópicos mencionados previamente y a partir de éstos se diseñaron preguntas específicas, con el propósito de comprender las nuevas infancias, los vínculos entre niños y adultos, y la influencia de los cambios sociales.

Tópico 1: "Defina en pocas palabras lo que para usted significa ser un niño", "Cuando fue padre/madre ¿Hubo cambios en esas ideas? ¿Cuáles?”, “Cuáles son las cosas que su hijo/a necesita de usted? ¿Qué le pide habitualmente?”, “Describa en una frase ¿Cómo fue su propia niñez?", "¿Qué similitudes o diferencias encuentra entre su propia niñez y la de su hijo/a? Tópico 2: "Elija hasta cinco palabras para definir su experiencia como hijo/a", "¿Qué diría usted que es ser mamá/papá?”, “Qué es lo que más le gusta de ser madre/padre?”, "Mencione las principales dificultades que se le presentan como madre o padre ¿Cómo las resolvió?", “¿Puede identificar a alguien que le haya enseñado a ser madre/padre?”.

Tópico 3: "¿Qué es lo que más le preocupa de la realidad actual en relación a la crianza de su hijo/a?", "Enuncie dos o tres tareas habituales que le pide a su hijo/a ¿Cómo le responde el 
niño/a?".

Tópico 4: "Relate brevemente una situación de crianza que le produjo frustración ¿Cómo la resolvió?", "Describa brevemente ¿Qué expectativas a futuro tiene sobre su hijo/a?". Tópico 5: "Relate alguna experiencia importante en el desarrollo de su hijo/a (adquisición del lenguaje, cuando dejó los pañales, cuando ingresó al jardín o escuela, etc.), incluyendo como Ud. como mamá o papá participó", "Enuncie en una frase qué postura tomaría ante la presencia de conflictos o dificultades de su hijo con sus pares o con adultos", "Comente en pocas palabras qué lugar ocupa la tecnología en la dinámica familiar”.

En concordancia con lo ya expuesto, se hace referencia a que los/as niños/as se encuentran en proceso de constitución de su subjetividad, entramada con otros y en relación directa con la época histórica en la que vive. A causa del escenario impuesto por la pandemia, se creó un protocolo para indagar cómo los niños/as de entre 4 a 10 años de la ciudad de Río Gallegos estaban atravesando y elaborando la pandemia y la cuarentena. A partir del diálogo entre el adulto y el niño se busca averiguar principalmente el tipo de información que destacan, el lugar de los adultos en la situación de cuarentena, la circulación de información, las angustias, los procesos de simbolización de la situación, las referencias a la escuela.

Continuando con lo mencionado anteriormente es preciso preguntarse sobre los efectos en relación a la salud mental. Cabe señalar que el papel de los adultos en cuanto a la infancia es relevante, ya que deben estar en condiciones psíquicas de ofrecer al niño/a elementos para la elaboración de estos acontecimientos y que así no resulten traumáticos.

De acuerdo con Piaget (2001) el método clínico pretende reunir los recursos del test y de la observación directa, evitando sus respectivos inconvenientes. En concordancia con esto, se les solicitó a los adultos que tenían contacto directo con los/as niños/as una grabación de un diálogo. Este último partiría de la pregunta abierta: “¿qué es para vos la cuarentena?", obteniendo un relato de qué piensan, sienten, extrañan. Por consiguiente, se procedería de acuerdo con la perspectiva clínica, sin imponer contenido y dejándose dirigir por el niño/a. Una vez finalizado este relato libre, se les solicita un dibujo mediante la consigna de "¿Qué te gustaría hacer cuando termine la cuarentena?" o sobre aquello que estuvieron charlando con anterioridad.

En coincidencia con Aberastury (1986) se tuvo en cuenta que a veces el niño no puede expresarse con palabras y lo hace con dibujos, o a la inversa. De esta manera se puede tomar contacto con las emociones, deseos, ideas y pensamientos. Cuando un niño dibuja, inventa y crea, expresa situaciones presentes o pasadas, y la incidencia de estas en su mundo interior. De esta manera es considerado como un modo central de simbolización en las infancias. A partir de la simbolización se pone en marcha la representación como actividad intelectual, suponiendo una relación entre significado y significante, permitiendo analizar los movimientos de asimilación y acomodación. Se puede tramitar por esta actividad cognoscitiva de manera subjetiva e intelectualmente recortes de la realidad.

\section{Resultados}

En lo que refiere a las encuestas cualitativas realizadas a padres/madres de niños entre 4 a 10 años se pudieron obtener distintas representaciones en el marco de los tópicos establecidos y las preguntas específicas.

En relación a las concepciones sobre la infancia, definen a los niños/as como personas que necesitan protección y cuidados, seres inocentes, sagrados, de amor, inquietos, sinceros, vinculados a la felicidad, curiosidad, aprendizajes y juego.

La noción de infancia depende del contexto, tiene un carácter histórico y cultural. Según 
Casas (2006) a lo largo de la historia occidental hubo distintas ideas sobre la infancia, en algunos momentos positivas y en otros, negativas. Teniendo en cuenta las respuestas, se asocia mayoritariamente a la infancia como representación positiva, idílica y feliz, donde se encuentra presente la inocencia, pureza y vulnerabilidad. Así, se pueden observar contestaciones como:

"Ser un niño significa para mí poder jugar aprender y disfrutar la vida desde una perspectiva pura e inocente".

"Es una personita que no conoce la maldad, no sabe del peligro, que es super dependiente de los papas para todo".

"El niño es un sujeto en desarrollo que requiere del acompañamiento y protección de los y las adultas referentes como así también de las instituciones".

"Inocencia, despreocupación, dulzura, vulnerabilidad, simpatía”.

En cuanto a aquello que los/as hijos/as demandan a sus padres, cabe destacar la función de amparo y sostén donde están presentes ciertas acciones como el alimento, cuidados, higiene, abrigo. Además, se reconoce como importante en el desarrollo del niño el brindar amor, la comunicación, el vínculo afectivo. La atención, bienes materiales (como la tecnología), juego, información, tiempo, compañía, ayuda en las tareas.

"Me piden desde lo escencial, como ropa, alimentos, ayuda en las tareas etc. como también participar de sus juegos".

“Mimos, jugar a algo, necesidades básicas (abrigarse, comer), mirar la tele o celular”.

“Atención, juegos, amor, tiempo, lo pide de forma explícita”.

Sobre cómo fue su propia niñez se destaca en algunos que fue feliz, divertida, con libertad, mientras otros la describen como difícil, triste, muy cambiante en cuanto a emociones.

Es así como las familias, tal como lo menciona Gallego Betancur (2011) "son consideradas como la unidad básica de la organización social, y las primeras encargadas de brindar protección, compañía, seguridad, afecto y apoyo emocional a sus hijos e hijas durante toda la vida, especialmente en el proceso de crecimiento y desarrollo" (p.66). Siguiendo esta línea expresa que "criar es cuidar y cuidar es más que alimentar, implica una interacción en la que la demostración de afecto es fundamental y fundante de humanidad" (p.69). Es por esto que se entiende en las respuestas, que los/as niños/as no sólo demandan atenciones básicas referidas a la nutrición, la higiene, etc., sino que también requieren del aspecto afectivo, como el amor. Cuando se habla de las similitudes o diferencias entre las niñeces de las/los madres/padres respecto a sus hijos, algunos las mencionan como similares en cuanto a la felicidad, el amor, acompañamiento, relaciones familiares, con amigos, juego; y otros como distintas por la contención familiar, circulación de información, libertades, más presencia de tecnologías, la situación económica y el tiempo compartido.

"Similar la felicidad, y diferencias que hoy a nuestros hijos les permitimos poner en palabras todo aquello que les molesta, constantemente charlamos, prestando atención constantemente sus emociones". 
"diferencias: no me preguntaban que quiero yo, no tenía opción de elegir, ni siquiera que usar, no podían asistir por trabajos a actos importantes, nosotros nos organizamos siempre para estar siempre en sus presentaciones, no tenía actividades extra escolares, ellos hacen lo que quieren, danza, gimnasia artística, etc. me enseñaban con gritos, ahora no, si tenía más libertad de salir a la vereda a jugar sola, nosotros los acompañamos siempre porque tenemos temor".

"Mis padres concebían la niñez de otra manera donde no se podía opinar o cuestionar, mis niñas tienen espacio para hablar pensar y decir. Tengo en cuenta sus singularidades y busco respetarlas siempre guiando su proceso, sin correrme del rol de adulto responsable."

\section{"Ella tiene mayor acceso a la tecnología, mayor estimulación y menos problemas económicos".}

En este punto, Aranda (s.f.) explica que las transformaciones socio históricas producen modificaciones en la representación social acerca de los niños y las familias, esto ayuda a entender por qué existen estas similitudes y diferencias en cuanto a estas niñeces, dado que las familias se encuentran atravesadas por factores sociales, políticos, estructurales e ideológicos, incidiendo en las relaciones, las prácticas de crianza, la comunicación, etc. que tienen repercusión en cada individuo y familia.

Para definir su experiencia como hijo/a se destacan algunas sólo positivas, otras sólo negativas, y otras ambiguas (como buena-mala; Afectuosa-laboriosa, etc.).

En este punto se hacen alusión a las funciones familiares de sostén y corte, es decir, los cuidados que le brinda el otro, la transmisión de valores, ideales, modelos en cuanto a lo prohibido y lo permitido. Por ejemplo, dar amor, establecer límites, contención, cuidados, mimos, inculcar valores, respeto, etc.

También se hace referencia a las actividades de recreación y juego, como educativas artísticas; a vivencias satisfactorias, como respeto, amabilidad, alegría, etc.

“responsabilidad, adaptación, aprendizaje, valores, educación”.

“Limites, actividades educativas, artísticas, apoyo familiar”.

\section{“Amor Alegría Libertad Estudio Generosidad".}

Cabe destacar que el afecto en los procesos educativos es importante, cuando el cariño y la ternura se encuentran presentes puede reflejarse, tal como lo menciona Barudy y Dantagnan (2005) en un modelo educativo nutridor y bientratante.

Se encuentran presentes en los relatos situaciones conflictivas o vivencias negativas, como el suicidio, depresión, abandono, soledad, traumas, sumisión, desequilibrio, miedos, etc.

"Abandono, dolor, falta de atención, exigencias extremas, falta de amor".

“Cómo hija todas malas. Triste Traumática Odio Suicidio Depresiva”.

“Responsabilidad temprana, inseguridad, falta de comprensión, sobre protección”.

Además, mencionan características propias de la etapa evolutiva como la rebeldía, caprichos, travesuras, etc. 
"Traviesa, caprichosa, amorosa, compañera, enojona".

No se puede dejar de lado que "Los niños y las niñas tienen derecho a vivir en un contexto de seguridad emocional, así como a disponer de lazos afectivos con adultos <<suficientemente disponibles $>y$ accesibles. Capaces de transmitirles una aceptación fundamental, de proporcionarles el apoyo indispensable para la aventura de crecer y un clima emocional donde la expresión de afectos sea posible" (Barudy y Dantagnan, 2005, p. 64). Es así como estos autores expresan que los malos tratos, consecuencia de las incompetencias de los padres provocan graves daños en los niños, aunque no siempre sean visibles.

Al hablar de qué es ser mamá/papá para ellos se destaca: la responsabilidad de otro a quien cuidar.

Algunas experiencias satisfactorias, viendo a la maternidad-paternidad como "algo hermoso", "lo mejor del mundo o que les pudo pasar", felicidad, por ejemplo:

"Es el mejor estado que puede tocarle a una persona".

Otras experiencias negativas, planteando la disconformidad, siendo la maternidad-paternidad como lo peor o una pérdida. Por ejemplo:

\section{"Pérdida de tiempo, plata y paciencia".}

También se mencionan dificultades, siendo una de las tareas más complicadas que existen, pero en su mayoría acompañado de algo positivo; la consideran un proceso que incluye desafíos, equivocaciones, aprendizajes constantes a nivel personal y en conjunto.

Barudy y Dantagnan (2005) mencionan que "El mérito de las madres y de los padres reside en el hecho de que deben responder a múltiples necesidades de sus hijos, necesidades que, además, cambian con el tiempo. Deben, por consiguiente, disponer no solamente de recursos y capacidades, sino también de plasticidad estructural para adaptar sus respuestas a la evolución de estas necesidades del desarrollo infantil" (p. 62). Es así como ser madre o padre es uno de los desafíos más difíciles y complejos que un adulto debe afrontar.

Ante la pregunta de qué es lo que más le gusta de ser madre/padre, resaltaron:

Aspectos relacionados a la crianza, incluyendo la responsabilidad, la puesta de límites, la educación, transmisión de valores y cultura, los cuidados, brindar tiempo, etc.

"Ver cuando mis nenes tienen buenas actitudes con los demás, como por ej de solidaridad sin esperar nada a Cambio. $O$ actitudes de respeto algo tan sencillo como por ej. Saludar al entrar a un lugar"

Se tendrá en cuenta que los niños/as aceptan someterse a normas porque son legitimadas por los valores de su cultura, especialmente si las normas y las reglas sociales garantizan el respeto de todos y permiten la emergencia de la justicia, la tolerancia, la solidaridad, el altruismo social y la ayuda mutua. "Tratar bien a un niño es también darle los utensilios para que desarrolle su capacidad de amar, de hacer el bien y de apreciar lo que es bueno y placentero. Para ello debemos ofrecerles la posibilidad de vivir en contextos no violentos, donde los buenos tratos, la verdad y la coherencia sean los pilares de su educación" (Barudy y Dantagnan, 2005, p. 75). 
En cuanto a vivencias satisfactorias se expresa, ver el crecimiento de sus hijos, cómo se superan, emocionarse por los logros, el amor, diversión, juego, etc.

"Las carcajadas naturales que te inundan y te contagian de experiencias simples. Ver las pequeñas cosas que va haciendo mientras crece. El abrazo, el beso o los mimos que te brinda".

"Disfrutarlos, verlos crecer y jugar con ellos".

Tal como será mencionado posteriormente en el protocolo aplicado a niños, el juego es uno de los pilares del desarrollo infantil, por lo que facilitan compartiendo con ellos vivencias gratificantes. Además, los espacios lúdicos son lugares de aprendizaje, se estimula el ser un sujeto activo en la construcción de la realidad.

En los encuestados se puede evidenciar como dificultad la puesta de límites, en cuanto al ejercicio de la autoridad, y de la crianza de los mismos, la dificultad para generar respeto.

"Como madre siento que algunas dificultades que se me presentaron han sido por ejemplo de poner límites, me cuesta bastante, es cierto que tengo un solo hijo y no es complejo... Pero en pequeñas cosas me cuesta poner límites".

"Las dificultades se presentan al momento de cuestionar el No alguna cosa o límites que se marcan. Se resuelven hablando y haciendo acuerdos".

"Poner límites ante la tecnología, ante los caprichos y sus estados de ánimos o malhumores. Aún intento resolverlos".

Ante esto, y relacionadas a las funciones mencionadas con anterioridad (sostén y corte) aparecen ciertas dificultades en la función de la autoridad y la puesta de límites, entendiendo que las funciones adultas son necesarias para introducir al sujeto en lo normativo, es decir, aquello que puede y no hacer.

Se mencionan también los caprichos como una dificultad, y la tecnología, en cuanto al uso de la misma, el tener que controlar y hasta ser utilizada como castigo/prohibición. Ante esto último, Goleman (1996) citado por Barudy y Dantagnan (2005) menciona que los niños necesitan ser ayudados para aprender a modular sus emociones, es decir, desarrollar una inteligencia emocional. Estos deben aprender a controlar los impulsos de sus comportamientos que pueden presentarse cuando desean algo o ante la frustración por no tener lo que quieren, ante el tipo de situaciones mencionadas en las encuestas se hace necesario, espacios de conversación o reflexión sobre las vivencias emocionales y formas de controlar las emociones, así también formas adaptativas y adecuadas de comportarse cuando se producen transgresiones. Además, explican que esta repetición de faltas se acompaña de una reflexión de los efectos, como también puede ser de castigos y actos reparativos.

Al preguntar si identifican a alguien que le haya enseñado a ser madre/padre, algunos expresan que no (lo ven como un aprendizaje constante, y que se puede hacer sólo buscando información) y otros hacen referencia a la madre, padre (otros familiares como abuela, tía, hermanos), pareja, amigas.

"En mi caso no hay alguien... Hubo una carrera docente que me permitió adentrarme en temas inherentes a la tarea materna". 
"Es un aprendizaje continuo. De mis padres puedo ver lo que no me gustó y lo que sí, para poder aplicarlo o no repetirlo con mis hijos".

"Si, mi papá, mi mamá, mi abuela a través de su cuidado".

Es pertinente destacar que el poder responder a las demandas y cuidados de un hijo/hija, protegerlos y educarlos, son resultados de complejos procesos de aprendizaje que se realizan en la familia de origen y en las redes sociales primarias, por supuesto también influidos por la cultura y las condiciones sociales de la persona. Los modelos de crianza se transmiten de generación en generación como fenómenos culturales; las formas de percibir y comprender las necesidades de los niños están incluidas implícita o explícitamente, lo mismo que las respuestas para satisfacer necesidades y maneras de protección y educación.

Sobre las preocupaciones de la realidad actual en relación a la crianza de su hijo/a, se destaca el uso de la tecnología, por el acceso ilimitado a la información y el tiempo que les dedican a las redes sociales, lo cual genera temor e inseguridades frente al peligro al que pueden exponerse. Vasen (2008) explica que la infancia ha variado y la subjetividad de los niños en la época actual se constituye de manera distinta y sobre diferentes soportes. La irrupción de la tecnología y los medios masivos son uno de esos cambios, que por supuesto inciden en los niños, esto recuerda también a uno de los puntos anteriores, por las diferencias mismas entre las infancias de los padres-hijos. Además, se encuentran enormes dificultades para poner límites a los hábitos ligados al consumo de sus hijos. Es posible mencionar que hay mayor acceso a la tecnología en la actualidad, y esto representa un desafío para las familias. Los niños se presentan como consumidores precoces con alcance a dispositivos tecnológicos, encontrándose multiconectados e hiperestimulados. Como ejemplo se puede observar el siguiente relato:

"Que se apegue mucho a la tecnología a las redes y no cree vínculos verdaderos con las personas y pierda habilidades para entablar relaciones de cualquier tipo y no identifique cuando está en peligro".

También se encuentran presentes preocupaciones relacionadas a la calidad educativa, por el bajo nivel educativo y la discontinuidad en los aprendizajes. Aquí también se involucra la situación de pandemia. Además, influye la falta de contactos, vínculos y relaciones con los otros. Por ejemplo:

"La desafiliación. La falta de contacto con sus entornos comunes, la falta de relación con sus pares, lo considero de suma importancia”.

La escuela es muy importante en el desarrollo de los niños. Es así que permite no sólo la función de educar, sino que también otorga la oportunidad de relacionarse con otros, en palabras de Vasen (2008) "la escuela socializa, sirve de puente e interfaz dentro/fuera entre la "intimidad" familiar y el "afuera" social que, como hemos planteado, ya está "adentro" como extimidad. La escuela sigue siendo el primer espacio real en el que se experimenta lo diverso, donde se experimentan las diferencias, donde se registra al otro y se recibe la mirada del otro" (p. 76).

Por supuesto que las funciones de crianza de las familias no se realizan de manera aislada, dado que el contexto influye en el ejercicio de las mismas. Es por esto, que se relatan también problemáticas asociadas a la sociedad cambiante, la situación económica, políticas educativas $\mathrm{y}$ de igualdad, la pobreza, el machismo, grooming, adicciones, inseguridad (en distintas 
formas como la violencia, maltrato, abuso sexual, pedofilia).

Se solicitó que enuncien dos o tres tareas habituales que le piden a su hijo/a y cómo responden ellos. Se mencionan las tareas cotidianas del hogar (orden, limpieza, mantenimiento de la casa), tareas escolares, actividades relacionadas con la salud e higiene (bañarse, alimentarse, cepillarse los dientes, tomar medicamentos, etc.), actividades de recreación y juego, y otras como la transmisión de normas sociales, comportamientos con otros, valores. Como fue mencionado con anterioridad, todo esto también se asocia a las funciones parentales de sostén, contención y límites, donde hay una búsqueda del logro de la autonomía y responsabilidad de sus hijos/as. Por ejemplo:

\section{"Poner la mesa, higienizarse, hacer los deberes... A las dos primeras bien, a la última le cuesta bastante, debe adquirir sentido de responsabilidad".}

En cuanto a cómo resolvieron situaciones de crianza que les han producido frustraciones, se privilegia el diálogo, en otros el castigo (sacarle o no permitirle algo que le gusta), otros manifiestan no saber cómo resolver la situación, buscando ayuda externa (profesionales). Es importante destacar que, según Barudy y Dantagnan (2005) existe la necesidad de pedir, aportar y recibir ayuda de redes familiares, sociales, institucionales y de profesionales cuyo fin es la promoción de la salud y el bienestar infantil. Estos, deben conformar redes de apoyos confiables para contribuir a las parentalidades.

Es posible visualizarlo en algunas respuestas como:

"Situación q nos produjo frustración que el niño no quisiera hacer la tarea! Lo resolvimos sacándole lo que más le entretenía, si lo quería de vuelta tenía que cumplir con sus tareas...”.

\section{"Me produce frustración las conductas violentas, enojos... La resuelvo poniéndome a su altura mirando sus ojos y terminamos hablando".}

Algunos se mencionan en la experiencia importante en el desarrollo de su hijo/a como participante activo, de manera positiva, por ejemplo, acompañándolo con información, materiales, tiempo destinado, felicitando, siendo emotivo, etc.; de manera negativa, por ejemplo, sintiéndose aislado de la situación; como una experiencia difícil; otros, sólo relatan la experiencia sin incluirse en la misma. No se puede dejar de lado que en el desarrollo de las niñeces también es necesario la presencia de ciertos estímulos desde las madres/padres dado que los mimos ofrecerán apoyo y retos para estimular los logros de sus hijos, donde el reconocimiento y la gratificación se hacen presente.

Si se presentara un conflicto o dificultad de su hijo/a con sus pares o adultos, se plantea abordar la situación mediante el diálogo, escucha, comprensión, tolerancia, el respeto ante las diferencias, destacando la necesidad de disculparse, pensando el bienestar de su propio hijo/a. En este punto también se resalta la autoridad y los límites. Y que, si son dos niños los involucrados, se debe conversar entre padres. Otros mencionan la protección. Además del afecto, no se puede dejar de lado la comunicación, ya que si se comunican en un ambiente de escucha mutua, respeto y empatía manteniendo una jerarquía de competencias, se hace presente el modelo educativo bientratante.

A partir de los diálogos fue posible observar la elaboración cognoscitiva de acuerdo al pensamiento de sus etapas evolutivas, y los sentimientos de incomodidad con emociones displacenteras. Además, en cuanto a la información que poseen, no es procesada ni resignificada, sólo reproducida, es así donde vemos la insuficiencia de explicaciones que recibieron como también la dificultad para transitar el confinamiento. A su vez, se resalta 
cómo los niños manifiestan distintas percepciones y vivencias. Se hace hincapié en que hay más tiempo compartido con la familia, postergando el inicio de la socialización secundaria, con temores inconscientemente transferidos por los padres, destacando a la familia, amigos, la soledad y el miedo.

Puleo Rojas (2012) expresa que el dibujo del niño representa un medio único para acercarse a la realidad, revelando aspectos que difícilmente se podrían comprender a través de otros modos de expresión, además que constituye un lenguaje espontáneo que es más agradable para el mismo. De esta manera, se pudo visualizar las tramitaciones y simbolizaciones de los niños/as. Se destacan escenas donde se comparte con la familia, amigos, y en otros la soledad. Está presente el miedo, graficando al coronavirus corporizado acechando, o aquel contra el que hay que pelear. Por el contrario, aparece el adentro como seguro (sus casas).

También muestran lo que extrañan, el exterior, la naturaleza, las plazas, la ciudad, estar acompañados de sus amigos, andar en bicicleta, estar en el patio, jugar a la pelota. Por supuesto, todo esto fue limitado por la crisis del Covid-19, que supuso entre otras medidas la limitación en la circulación, como también la suspensión de las actividades presenciales, como la educativa.

En síntesis, ante estas expresiones de cómo están atravesando las infancias la cuarentena, es sumamente necesario que los adultos sostengan a sus hijos/as en este escenario de incertidumbre e inseguridad, teniendo un gran desafío y responsabilidad, permitiendo la circulación de información adecuada para su edad, manejar sus propios temores para evitar transferirlos a sus hijos de manera irreflexiva, es aquí donde el contacto físico se visualiza como algo peligroso y siendo necesario ofrecer un espacio para sentirse seguros.

\section{Discusión}

Si se consideran los objetivos generales del proyecto de investigación en que se desarrolló la actividad de la becaria, y las readecuaciones metodológicas en contexto de pandemia, cuando se analiza la puesta en escena de las funciones adultas previas al aislamiento social y las modificaciones sufridas por el predominio de la virtualización; se comprenden la persistencia de las dificultades de las familias frente a la escolarización y una necesidad de resignificación de sus funciones frente a la situación generada por las medidas sanitarias.

Las familias deben seguir ejerciendo sus funciones de sostén y límite; sin embargo, tomando en cuenta la escolaridad virtual y el cumplimiento de las tareas escolares se ven afectadas por las angustias de niños y niñas por las restricciones en el contacto socio-afectivo y los temores originados por el peligro que significa el virus. La organización de las rutinas diarias que como se ha dicho en la línea investigativa- son organizadoras psíquicas y sociales, se ven alteradas por la irrupción de las cuestiones escolares en ellas.

La pandemia perturba el orden y la organización de la cotidianeidad pre-existente; los adultos se ubican como responsables de garantizar la crianza, atravesados por la incertidumbre y las preocupaciones que la situación pandémica conlleva. Un nuevo orden de cosas, repercute en los vínculos intra-familiares afectados por una situación disruptiva.

Así los adultos se ven obligados a un cambio de posicionamiento para poder sostener la escolaridad virtual y las nuevas dinámicas familiares. Se hace imprescindible entonces, pensar en las huellas que dejará la pandemia tanto en los lazos sociales como en la subjetividad de cada niño, niña y adolescente.

Se venía sosteniendo que se han producido nuevas formas de concebir a las infancias y adolescencias, quedando a su vez cuestionadas las funciones adultas. El contexto de crisis sanitaria originada por la pandemia, ha incluido una nueva variable en esas transformaciones que requerirán seguir siendo investigadas. De la misma manera, las relaciones entre las dos instituciones fundantes de subjetividad familia y escuela, también han visto alteradas 
imprevistamente sus funciones y su articulación; por ello, es dable generar nuevos interrogantes y abordajes para comprender sus efectos.

\section{CONCLUSIONES}

Se ha podido resaltar como resultado de la investigación la importancia de la posición subjetiva del enseñante, en tanto el mismo es responsable de acompañar y sostener a los niños con certezas, ejerciendo las funciones educativas y de crianza. Es así como es un modelo identificatorio que permitirá el despliegue de la subjetividad de los niños, sin dejar de lado la importancia del aprendizaje, que podrán atravesar si ubican a los adultos como autoridad. De esta forma, el adulto debe ofrecer un espacio de seguridad, incluso sabiendo que el vínculo entre ambos está atravesado por el contexto. Esto fue comprobado con el estudio de los resultados del protocolo a niños, donde se pudo observar entre otras cuestiones el lugar de los adultos en la cuarentena. Las encuestas cualitativas empleadas fueron de utilidad para comprender las nuevas infancias, subjetividades y las formas de aprender y enseñar, dando continuidad al instrumento creado con anterioridad.

\section{RECOMENDACIONES}

La línea de trabajo que se ha desarrollado está atravesada por el compromiso ético de la universidad con la comunidad en que se inscribe; trabaja en procesos investigativos de mutua incidencia en el campo disciplinar y en la comunidad donde se realizan intervenciones profesionales.

Sus consideraciones intentan mostrar de qué modos se hacen posibles, ciertas respuestas que atenúen los crecientes malestares psico-sociales particularmente ligados al aprendizaje humano y a los vínculos entre adultos que enseñan-niños y niñas que aprenden.

Los sucesivos análisis de esta investigación y de las que la anteceden, revelan la necesidad de reconstruir puentes entre familias y escuelas, entre adultos y niños-niñas-adolescentes, a fin de reconstruir a través del conocimiento generado intervenciones que disminuyan los efectos adversos de los desencuentros que han sido señalados.

La tarea permite situarse reflexivamente como protagonistas en la compleja red de relaciones y en las propias voces de los actores sociales que interpelan la tarea de los investigadores. Los conocimientos generados permiten la planificación de acciones concretas de transferencia para visibilizar las problemáticas identificadas y abordarlas en proyectos destinados principalmente a los adultos que crían y educan a niños, niñas y adolescentes. Así mismo, sus resultados requieren ser incluidos como temas principales en la formación de los profesionales, en particular psicopedagogos y profesores.

\section{AGRADECIMIENTOS}

Agradezco el acompañamiento de la directora de beca Mg. Patricia Arias, como también de las demás integrantes del equipo por compartir conmigo todos sus conocimientos, experiencias y pasión por lo que hacen, dado que esto me permite seguir formándome y profundizar en el campo de la psicopedagogía clínica e investigativa. 


\section{REFERENCIAS BIBLIOGRÁFICAS}

ABERASTURY, A. (1986). Aportaciones al psicoanálisis de niños. Editorial Americana.

ARANDA, N. (S.F.). Familia y desarrollo infantil.

BARUDY, J., DANTAGNAN, M. (2005) Los buenos tratos a la infancia. Parentalidad, apego y resiliencia. Barcelona: Gedisa.

CASAS, F. (2006). Infancia y representaciones sociales. Política y Sociedad, 43 (1), 27-42.

FAAS, A. (2018) Psicología del desarrollo, Niñez. Córdoba: Brujas.

FERNÁNDEZ, A, (2002) Poner en juego el saber. Psicopedagogía clínica: propiciando autorías de pensamiento. Buenos Aires: Nueva Visión.

GALLEGO, T. (2012). Familias, infancias y crianza: tejiendo humanidad. Revista Virtual Universidad Católica del Norte, 35, 63-82. Recuperado de https://revistavirtual.ucn.edu.co/index.php/RevistaUCN/article/view/352/667

HAMMER, E. (2008) Test proyectivos gráficos. $2^{\mathrm{a}}$ ed. $3^{\mathrm{a}}$ reimp. Buenos Aires: Paidos.

JANIN, B. (2012) El sufrimiento psíquico en los niños: psicopatología infantile y constitución subjetiva. Buenos Aires: Centro de Publicaciones Educativas y Material Didáctico.

JIMÉNEZ CORTÉS, R. (2007). Aportaciones metodológicas a la investigación sobre género en educación. Fuentes, 7, 65-78.

PIAGET, J. (2001). La representación del mundo en el niño. $9^{\mathrm{a}}$ ed. Madrid: Ediciones Morata.

PULEO ROJAS, E. (2012) La evolución del dibujo infantil. Una mirada desde el contexto sociocultural merideño. Educere, 16 (53), 157-170.

VASEN, J. (2008). Las certezas perdidas. Padres y maestros ante los desafíos del presente. Buenos Aires: Paidós. 